\title{
Morir por espada, Helena, vv. 298-302 ${ }^{1}$
}

To die by Sword, Helen, vv. 298-302

\author{
Carmen Morenilla Talens \\ Universitat de València \\ carmen.morenilla@uv.es
}

\begin{abstract}
Resumen: En las tragedias de Eurípides algunos personajes reflexionan sobre el mejor modo de suicidarse. Lo hace Helena en la tragedia homónima en varias ocasiones, incluyendo los vv. 298 ss., que han sido atetizados por varios editores. En este estudio apoyamos la autenticidad de esos versos, en los que Helena manifiesta su preferencia por la muerte por espada e indicamos las causas de esa preferencia.
\end{abstract}

ABSTRACT: Some of Euripides' tragic characters reflect upon the best means of committing suicide. One of them is the Helen of the homonymous tragedy, particularly in lines $298 \mathrm{ff}$., which have been generally suppressed by the editors. This article emphasizes the authenticity of these lines where Helen expresses a preference for a death by sword, providing also the reasons behind such preference.

PAlABRAs Clave: Eurípides, Helena, suicidio.

KEY WORDS: Euripides, Helen, suicide.

RECIBIDO: 28 de febrero de 2013 - ACEPTADO: 26 de abril de 2013.

1. En las tragedias en diversas situaciones, siempre intensas, y por boca de personajes diferentes, incluido el coro, se barajan distintos modos de suicidarse o de matar a otra persona. ${ }^{2}$ Las tragedias muestran todo un catálogo de formas de matar o de matarse, desde el envenenamiento al que alude primero Ión en la tragedia homónima y después intenta Creúsa, ${ }^{3}$ a la muerte por inanición que busca para sí Fedra, pasando por muertes provocadas por encantamientos con ayuda o no de venenos, como la de la nueva esposa de Jasón y del padre de ésta en Medea. Incluso podemos ver anuncios de la muerte decretada como castigo a un delito cometido, un tipo de muerte que depende de la sentencia y, por ello, del tipo de delito,

\footnotetext{
${ }^{1}$ Este trabajo se enmarca en el Proyecto de I+D del Ministerio de Economía y Competitividad FFI2012-32071.

${ }^{2}$ Para la muerte en la poesía griega cf. García Pérez 2009.

${ }^{3}$ Ión con carácter general en los vv. 607 ss. se refiere a la tópica enemistad entre madrastra e hijastro y a los intentos de las mujeres de librarse de los hijos del marido mediante un procedimiento muy propio del ámbito femenino, el envenenamiento, vv. 616 ss.
} 
de los usos del lugar, etc., como, a modo de ejemplo, podemos ver en la sentencia de muerte que recibe Creúsa por lapidación en Ión, ${ }^{4}$ que, en cambio, en los vv. 1266-1268 se convierte en muerte por despeñamiento. ${ }^{5}$

El suicidio, la muerte por propia mano, tiene un papel muy destacado en la tragedia, en especial en Sófocles y Eurípides; también ha sido objeto de estudio y reflexiones desde la Antigüedad, sobre todo por sus implicaciones morales. ${ }^{6}$ En época moderna, desde que en 1897 Emile Durkheim publicara Le suicide, se ha convertido en un campo de estudio multidisciplinar con una copiosísima bibliografía. También en lo que hace al mundo clásico y particularmente al suicidio en la literatura griega, son ya considerables los trabajos que lo abordan. ${ }^{7}$

Pero, a pesar de esa presencia del suicidio tanto en la vida real como en la literatura, encontramos en los textos griegos una gran dispersión de expresiones para referirse a él, lo que no es en absoluto indiferente, sino que lleva a pensar que interesa más la manera de hacerlo y las causas que el hecho en sí. ${ }^{8}$ Con frecuencia en estas expresiones se utilizan términos

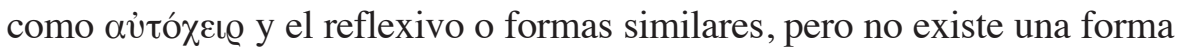
verbal específica equivalente a nuestro "suicidarse" o "suicidio". 9 Varios

${ }^{4}$ En los vv. 1111 s., en boca de un siervo que anuncia al coro la decisión de las autoridades ante el intento de envenenamiento de Ión, repetido al final de la resis, vv. 1222 s. y en boca del coro en vv. 1237 y 1240 (con respecto a ellas mismas). Acerca de las diferentes condenas capitales cf. Cantarella 1996, apartado "La lapidación como venganza en los trágicos y en la realidad social", pp. 69 ss.

${ }^{5}$ Se trata de unos versos muy expresivos en los que, tras comparar la sangre de la Gorgona con el veneno que por orden suya ha utilizado el viejo sirviente, ahora se compara su cabello con el de la Gorgona y su despeñamiento con el lanzamiento del disco, que, como muy plásticamente se dice, rebota en las piedras. En realidad, como señala Owen 1971, p. 143, y recoge Pellegrino 2004, es muy probable que no se deba ver aquí contradicción, sino la segunda parte de la condena: muerte por lapidación y despeñamiento del cadáver, puesto que el despeñamiento es una pena capital en casos muy graves, en especial por sacrilegio, probablemente por las consecuencias que comporta en el cadáver, destrozado e insepulto.

${ }^{6}$ Cf. Garrison 1991, y van Hooff 1999.

${ }^{7}$ Cf. Thalheim, R. E., s. v. "Selbstmord"; Garrison 1987, reelaborado y ampliado en 1995; van Hooff 1990; Loraux 2004; Seidensticker 2005.

${ }^{8}$ Cf. Gernet 2001, en su prefacio, llama la atención sobre la importancia de los términos y los conceptos que transmiten en el ámbito jurídico y moral, pp. 5 ss.

9 Tampoco el latín clásico tuvo un término específico: el primero en utilizar suicidium fue T. Browne, Religio Medici, sect. XLIV, escrito en 1636 y publicado en 1642. Cf. Navarro Antolín 1997 y Beltrán 1993, para los giros en latín. 
términos compuestos en contextos muy concretos adquieren este significa-

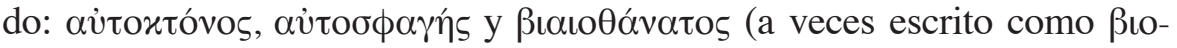

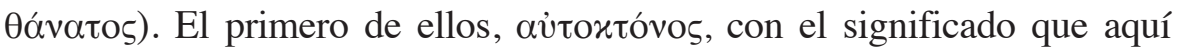
nos ocupa, aparece en un fragmento de Esquilo, si la reconstrucción es correcta. Se trata del fr. 451q R (P.Oxy. 2256), en los últimos versos, 16 s., al referirse al suicidio de Ayante:

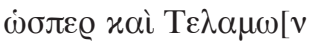

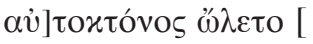

Como también [el noble hijo de] Telamón por propia mano pereció

Esquilo utiliza el mismo adjetivo con un significado diferente en Siete contra Tebas. Tras la resis en que Eteocles asume que él se enfrentará a su hermano (vv. 653-676), la corifeo le pide que no lo haga puesto que la mancha de ese tipo de muerte no envejece, vv. 681 s.:

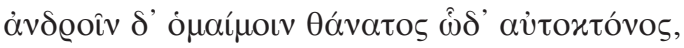

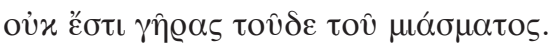

de dos hombres de la misma sangre la muerte así, uno a manos del otro, no hay vejez para esta mancha.

El significado de aủtoxtóvos está muy bien explicado en el mismo

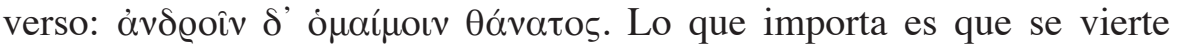
sangre del mismo genos, razón por la cual lo utiliza Esquilo en forma adverbial en esta misma tragedia para referirse a esas mutuas muertes en el v. 734, y en Agamenón, v. 1635, en boca del coro para aludir a la de Agamenón por Egisto, y Eurípides en Medea, v. 1254, también lo pone en boca del coro para tratar la muerte de los niños a manos de su madre.

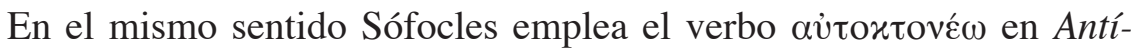
gona, v. 56, para referirse a la mutua muerte de los dos hermanos y en

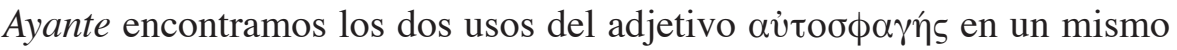
verso, el genérico referido al linaje y el específico referido al suicidio en la famosa resis final de Ayante en unos versos muy expresivos en los que pide a las Erinias que mueran como él quienes han causado su muerte, los Atridas, vv. 841 s.:

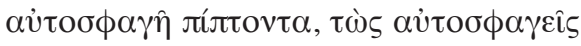

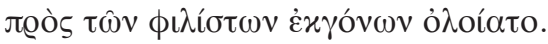


[a mí] que caigo herido por propia mano, así mueran por las propias heridas de los descendientes más queridos. ${ }^{10}$

Es evidente, pues, que con estos adjetivos los autores se refieren al derramamiento de sangre del propio linaje, sea la sangre de uno o la de un miembro de su genos. ${ }^{11}$ Y lo mismo podemos ver en Alejandra de Licofrón, poema en el que este artificioso autor utiliza el adjetivo aủ en los dos sentidos. En los vv. 437 s., al hablar de la muerte de Esténelo, se alude a la contienda que enfrentó a dos hermanos, Eteocles y Polinices:

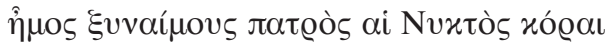

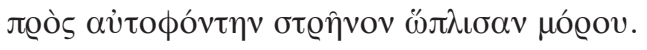

cuando las hijas de la Noche incitaron a los del mismo padre a un deseo de mutua muerte.

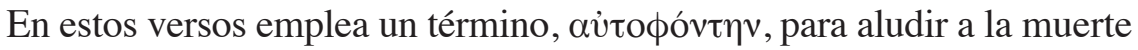
en el propio genos, y a continuación, vv. 439 ss., habla de la muerte de Anfíloco y Mopso:

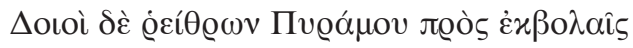

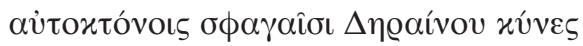

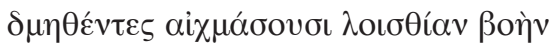

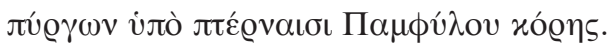

Dos de las corrientes del Píramo por golpes de mutuas heridas, como perros de Dereno domesticados, pelearán la postrera lucha a los pies de las torres de la hija de Pánfilo.

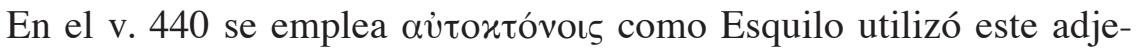
tivo en Siete contra Tebas para hablar de los hijos de Edipo que se dan

${ }^{10}$ Estos versos no han sido aceptados unánimemente; los atetizan, entre otros, Dawe y M. P. Pattone, mientras que otros los mantienen, como Dain en su edición para Les Belles Lettres.

${ }^{11}$ Este uso es el que tiene el adjetivo aủ rirse a la muerte a manos de alguien del propio genos: así lo vemos en Ag., v. 1091, junto

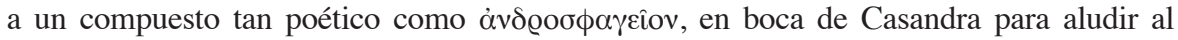
asesinato del rey por su esposa; y en Sept., v. 850, en boca del coro, que acaba de conocer la noticia de la mutua muerte de los dos hermanos. El mismo uso podemos ver, en forma adverbial, en Aesch., Supp., v. 65, para referirse a la muerte de Itis a manos de su madre. 
mutua muerte. Pero en el v. 714 del mismo poema, Licofrón lo usa para designar el suicidio de las Sirenas cuando Odiseo pasa de largo con su barco:

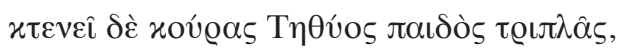

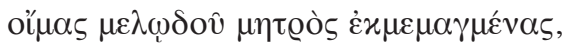

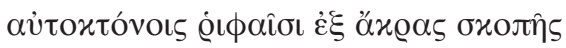

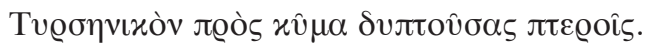

Causará la muerte de las tres hijas del hijo de Tetis, que aprendieron los cantos de la melodiosa madre, ellas con suicidas saltos desde alta roca en la ola del Tirreno se hundirán con sus alas.

En Licofrón, por lo tanto, vemos utilizado el término en los dos senti-

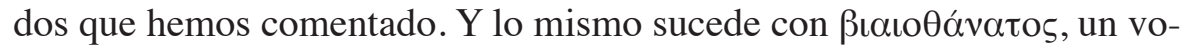
cablo que aparece en autores tardíos como Ptolomeo, Paulo Alejandrino, Olimpiodoro, entre otros, donde significa muerte violenta y en ocasiones específicamente suicidio, como leemos en Ökumenischen Heiligenlexicon de J. Schäfer: "Cassianus collat. XI de Discretione, cap. 5 per bio-

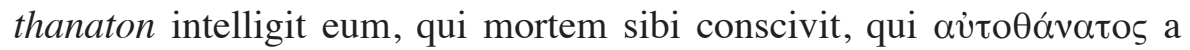
Graecis dici solet". 12

Pero este término, aủtoӨávatos, no aparece hasta Plutarco, en concreto en Moralia. Cuestiones Griegas 293 b-f, donde explica las causas del suicidio de Carila y sus consecuencias. ${ }^{13}$ Cuando la Pitia se refiere

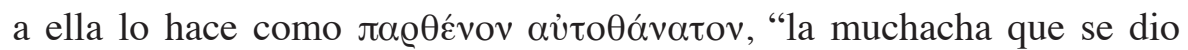
muerte a sí misma", 293 e. Para los versos de Helena que vamos a estudiar es interesante constatar que esta muerte, aunque es un suicidio, exige una reparación en la que ha de intervenir el que la provocó. ${ }^{14}$

Esta falta de un único término específico para designar el suicidio hasta época tardía, como decíamos, nos hace pensar que a los autores

${ }^{12} \mathrm{~S}$. v. en su obra De Sanctis martyribus Symphorosa cum septem filiis, p. 351.

${ }^{13}$ Carila, una niña huérfana de Delfos, acude al reparto de comida que hace el rey para paliar la hambruna, pero, humillada y golpeada por el rey, se aleja y se cuelga. Tras su muerte aumenta la hambruna y llegan enfermedades, que la Pitia atribuye al suicidio de Carila, por lo que a partir de ese momento se realiza todos los años un rito expiatorio que consiste en reproducir lo sucedido sustituyendo a la muchacha por una muñeca de trapo.

${ }^{14}$ Gernet 2001, p. 154, con respecto a homicidios, indica que la víctima exige reparación: "la mort violente suscite la fatalité mécanique du talion, la timôria est une libération qu'autorise et sanctionne l'ordre des choses". 
les interesaron más las causas, las maneras y las consecuencias de esas muertes, y a ello quisiéramos prestar atención en este trabajo, a los modos que elige para el suicidio Helena en la tragedia homónima y en particular a intentar entender mejor los vv. 298-302, donde la heroína reflexiona sobre la forma en que se va a dar muerte. Unos versos que han sido atetizados por varios editores, en unos casos por supuestos problemas de estilo o de comprensión de alguna expresión, en otros porque se considera inapropiado en una mujer el modo de morir por el que se inclina Helena.

2. Con frecuencia Eurípides hace que sus personajes, especialmente los femeninos, anuncien el deseo de morir y barajen diferentes medios para hacerlo, aunque no siempre lo lleven a la práctica, sino que sea sólo la expresión de una profunda turbación o de un temor exagerado, como es el caso de la joven Hermíone en Andrómaca, quien, una vez fracasado su plan de asesinar a Andrómaca y el hijo que ésta ha tenido con Neoptólemo, hace amago de suicidarse en una escena de claro tono paratrágico. Primero la nodriza de la joven, después la propia Hermíone hablan del intento de colgarse y, una vez los criados le han quitado la soga, del amago de utilizar la espada, en los vv. 802 ss. $^{15}$

También en Ión se habla en varias ocasiones de distintas formas de matar y de suicidarse, y en particular se barajan varias posibilidades sobre el modo en que podría Creúsa suicidarse, si fracasan sus planes de asesinar al joven Ión, recién reconocido por Juto como hijo. Pero esas palabras no están en boca de Creúsa, que muy al contrario de decidir suicidarse, huye de quienes quieren apresarla para que cumpla la condena de muerte que se le ha impuesto. Es el coro, que en esta obra tiene un papel muy activo, ${ }^{16}$ quien adelanta que su señora preferirá el suicidio

15 Para la interpretación de esta escena, cf. Morenilla \& Bañuls 2012.

${ }^{16} \mathrm{El}$ coro, formado por sirvientas de Creúsa que la han acompañado en su viaje a Delfos, adopta una actitud muy activa. Cuando Juto, una vez reconocido el hijo que Apolo le envía, decide llevarlo a Atenas; el joven Ión se resiste por diversos motivos, entre ellos por miedo a la reacción que podría tener la madrastra estéril, por lo que Juto acuerda con él buscar un momento propicio en Atenas para contárselo a Creúsa y le pide al coro que guarde silencio. Este motivo es habitual cuando habla a un coro femenino una heroína, entre quienes se produce una corriente de comprensión o incluso de simpatía. Éste no es el caso en Ión: el coro está formado por mujeres cercanas a Creúsa y quien les pide silencio es el señor, Juto, razón por la cual se siente obligado a añadir una amenaza de muerte si hablan. Pero el coro no sólo no obedece la orden, 


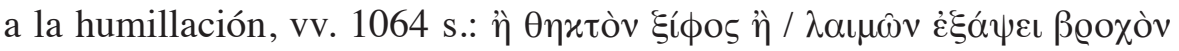

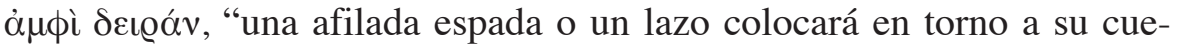
1lo". En opinión del coro, la señora no podrá soportar la humillación: recordemos que ella es la reina, la descendiente de Erecteo, como le echa en cara a Ión en el v. 1305, donde le advierte de la escasa herencia que él puede recibir de su supuesto padre. En esos versos el coro simplemente contrapone dos de los modos más frecuentes de suicidarse: por ahorcamiento y clavándose una espada o puñal.

Esta misma doble posibilidad vemos en Orestes, donde tampoco se llevarán a cabo los suicidios. Orestes, que acaba de ser condenado a morir lapidado por haber matado a su madre, ha conseguido que le dejen morir degollado de propia mano, vv. 946 ss., lo que es una concesión importante, que le permitirá morir como un guerrero, de herida de espada. También Electra debe morir el mismo día, como le comunica Menelao, quien le indica que ya puede ir buscando el puñal o el lazo, v.

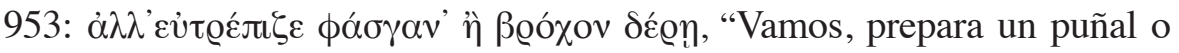
una cuerda para el cuello". Como en el caso de Ión, en la muerte de Electra sólo se contraponen los dos modos, sin dar prevalencia a uno de ellos, como vemos también más tarde en boca de Orestes refiriéndose a la muerte de los dos, vv. 1035 s.:

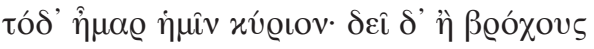

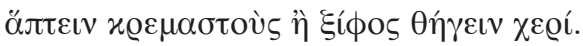

Éste es el día que manda en nosotros; hay que coger las cuerdas de la horca o afilar una espada a mano.

En los versos siguientes pide Electra a Orestes que sea él quien le mate para que no lo haga cualquier argivo, lo que sería un ultraje para ella; pero Orestes se niega, porque ya ha derramado sangre de la familia, la de la madre, y con la fría indiferencia hacia los sentimientos de Electra que ha mostrado siempre, le dice que se suicide ella como quiera, vv. 1039 s. $^{17}$

sino que añade leña al fuego: le anticipa la noticia a Creúsa incluso antes de que ella le pregunte lo que ha sucedido y no solamente lo cuenta, sino que carga las tintas contra Juto con reflexiones generales sobre la maldad y cobardía de los esposos que han tenido relaciones con otras mujeres.

${ }^{17}$ En el v. 1041 podría dar a entender Electra que se decanta por la espada, aunque puede que solamente se esté refiriendo a que no va a demorar la muerte. Apoya la primera 
Con respecto a esas enumeraciones de posibles maneras de suicidarse se suele indicar que el modo propiamente femenino es el ahorcamiento, ${ }^{18}$ mientras que la muerte vertiendo sangre, por espada o puñal, se considera masculina entre otras razones porque el ahorcamiento se produce en el interior de la casa, en el interior de la cámara conyugal, ámbito propio de la mujer. Pero en la tragedia las cosas son de otra forma: ${ }^{19}$ aunque el ahorcamiento sea el suicidio más frecuente entre las mujeres en la mitología e incluso en los relatos de hechos históricos o en textos médicos,$^{20}$ heroínas con papel destacado en sus obras se matan con la espada, como es el caso de Deyanira en Traquinias y Eurídice en Antígona, ambas en el interior de la casa, o Yocasta en Fenicias de Eurípides, que lo hace en el campo de batalla. O bien habían optado por otra forma, como Fedra en Hipólito, pero al final precipitan su muerte mediante la horca. Estas heroínas utilizan la espada en contextos especiales: Eurídice quiere verter la sangre y que recaiga sobre su esposo, Creonte, a quien considera responsable de la muerte, también por suicidio, del hijo que le quedaba vivo, Hemón, y lo hace ante el altar doméstico para reforzar la maldición; el suicidio por espada de Deyanira, en cambio, se atribuye a un resto del carácter belicoso de la Deyanira presofoclea o bien a que

posibilidad el deseo que manifiesta Electra de que una misma espada les diera muerte a ambos y compartir una tumba, vv. 1052 s., versos que pueden ser simple manifestación del deseo de compartir el mismo destino que el hermano, tanto en el modo de morir como en la tumba en la que han de ser enterrados. Pero también es cierto que esa manera de morir, por espada, cuadra bien con la actitud de Electra en esta obra, caracterizada por una impetuosidad y firmeza más propia de un varón, como muestra en la escena en que propone a Orestes y Pílades que maten a Hermíone, vv. 1177 ss. Cf. Synodinou 1998.

${ }^{18}$ Loraux 1998, passim, y 2004, en "El cuerpo estrangulado", pp. 222 ss., se ocupa de las diferencias entre estrangulamiento y ahorcamiento; en su opinión el ahorcamiento es la forma considerada femenina, incluso cuando optan por ella varones, lo que ejemplifica con situaciones procedentes del mito, la tragedia y la historiografía.

${ }^{19}$ Compartimos la opinión de Seidensticker 2005, aquí pp. 37 s., en el sentido de que debe matizarse la afirmación de que la muerte femenina por excelencia sea el ahorcamiento, al menos en lo que hace a los suicidios en la tragedia. Ésta es la primera forma de bajar al Hades que Heracles aconseja a Dioniso cuando el dios le pide ayuda en Ranas de Aristófanes, y sigue indicándole tras su rechazo a este primer procedimiento el envenenamiento y el despeñamiento, vv. 121 ss.

${ }^{20}$ Muy interesantes son las conclusiones a las que llega el tratado hipocrático Sobre la enfermedad de las muchachas, que busca causas fisiológicas a esa tendencia de las vírgenes a suicidarse; cf. Loraux 2004, pp. 234 s. 
la heroína quiere usar la espada en tanto que símbolo de su esposo, cuya muerte desencadena la suya propia; ${ }^{21}$ y la Yocasta de Fenicias se suicida con la misma espada que acaba de matar a sus hijos.

También Creúsa en Ión muestra una actitud similar a la de Eurídice en cuanto al deseo de verter sangre, aunque con diferencias notables. Cuando se ve acorralada por la gente de Delfos que quiere ejecutar la sentencia de muerte, sigue el consejo del coro y se acoge como suplicante al templo de Apolo. Ión se anticipa al resto de perseguidores e intenta sacarla del templo, pero ella le insta a que la mate, si desea, pero mediante la espada y en ese mismo lugar, e indica las causas (vv. 1309 ss.):

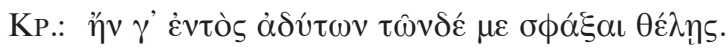

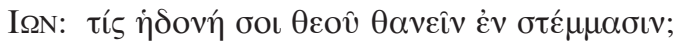

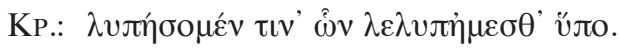

CREúsa: Salvo que dentro de este templo quieras degollarme.

Ión: ¿Qué placer hay para ti en morir entre las ínfulas del dios?

CREÚsA: Causaré penas a quien me ha causado penas a mí.

La intención de Creúsa es provocar un daño a Apolo, hacerle objeto de oprobio obligando a Ión a que vierta su sangre en el templo; con esto, en última instancia, hace al dios responsable de esa muerte: Apolo es el que le ha dado un hijo a Juto y el que la violó a ella permitiendo que expusiera al hijo habido de esa relación. El homicidio con derramamiento de sangre, cuando se produce en el interior de un templo, es un delito especialmente grave por la polución que provoca en un lugar sacro. ${ }^{22}$ En general, una muerte violenta tiene graves consecuencias, como bien señala L. Gernet: "le trouble qu'a déterminé dans le monde une mort violente, non seulement provoque une stupeur religieuse et nécessite les procédures de préservation rituelle, mais dans certains cas constitue pour les victimes un bénéfice posthume que savent capter les auteurs de la defixiones". ${ }^{23}$ Esos efectos sobre el que es considerado el responsable de la muerte, el que ha provocado la situación que lleva a una persona al

${ }^{21}$ Sobre estas muertes cf. Bañuls \& Morenilla, en prensa.

22 Sobre la importancia de la sangre en los sacrificios cf. Henrichs 2006.

${ }^{23}$ Gernet 2001, p. 66; en la p. 154 se refiere a la importancia religiosa de la sangre y su requerimiento de venganza. Cf. Rohde $1898^{3}$, Cap. "Elemente des Seelencultes in der Blutrache und Mordsühne”, pp. 259 ss. 
suicidio, creemos que son la causa de la reflexión que en Helena hace la heroína sobre el modo de morir que prefiere.

3. En Helena encontramos una situación especial. En esta tragedia son muchas las referencias a suicidios, unos ya realizados, otros previstos pero que no se llevarán a cabo. ${ }^{24}$ La propia heroína en la resis inicial apunta que se suicidaría, si no fuera por la promesa de Hermes de que volverá con su esposo. Ella se entera en una misma escena en diálogo con Teucro del suicidio de Leda, que se produce por ahorcamiento, ${ }^{25}$ la desaparición de los Dioscuros, de los que no se sabe si han muerto, y la de su marido, al que dan por perdido en el mar. Cuando explica al coro las noticias y el estado anímico en que se encuentra, dando ya por muerto a su esposo, se cree sin posibilidad de resistir el acoso de Teoclímeno y manifiesta que ante unas nupcias forzadas con un bárbaro prefiere la muerte, vv. 298-302:

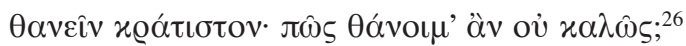

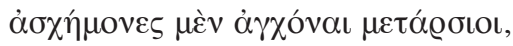

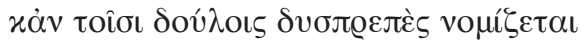

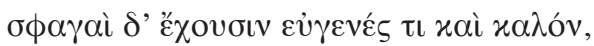

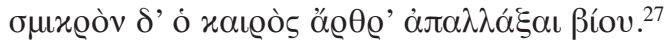

Morir es lo mejor; ¿cómo podría no morir de modo digno? Colgar por lo alto de modo inconveniente, incluso entre los esclavos se considera indecente; el degüello es en cambio noble y digno, el breve instante pone fin a las articulaciones de la vida.

Se ha pensado que de modo sorprendente en una mujer Helena manifiesta que rechaza la horca por indigna y prefiere la espada, a la que considera más honrosa y más noble. Estaría, pues, en cierta forma en la línea de

${ }^{24}$ Desde el comienzo vemos la presencia al mismo tiempo de la vida y la muerte, cf. Sousa e Silva 2005.

${ }^{25}$ Es significativo que sea la primera vez que se habla del suicidio de Leda. En $O d$., XI, vv. 298 ss., Odiseo junto a las otras almas ve a Leda, de la que sólo se dice que es la madre de Cástor y Póllux. Su muerte no interesa a Homero, como tampoco ha interesado a los estudiosos de mitología, como es el caso de Gantz 1993, pp. 318-322. Sobre Leda cf. Eitrem, R. E., s. v. "Leda".

${ }^{26}$ Mantenemos la lectura oủ de los manuscritos, frente a la modificación oủv de Estéfano que aceptan muchos editores.

${ }^{27}$ Hemos optado por la lectura que ofrece la edición de E. Calderón, más respetuosa con los manuscritos. 
las conclusiones a las que llega Loraux en el sentido de que la muerte por la horca es rechazada incluso por condenados, probablemente porque se trata de un tipo de muerte infamante, cuya aceptación podría significar una especie de sanción social de la infamia. Pero en los versos de Helena la heroína va más allá: no sólo rechaza la muerte por ahorcamiento, sino que valora positivamente la muerte por espada en una resis que, como bien señala M. Quijada, ${ }^{28}$ no tiene un carácter totalmente racional, como otras resis que siguen a expresiones del pathos, sino que está impregnada de elementos subjetivos, puesto que junto al dolor por la pérdida de la madre y los hermanos asume Helena como muy probable la muerte de Menelao a pesar del anuncio que le hiciera Hermes y al que ella aludió en el prólogo de la tragedia. En ese marco manifiesta ella la preferencia por un tipo de muerte, que contrasta, según algunos estudiosos, con los vv. 353 ss., donde ella misma parece no acordarse de esa reflexión y vuelve a referirse a las dos posibles maneras de suicidarse, empezando por el ahorcamiento:

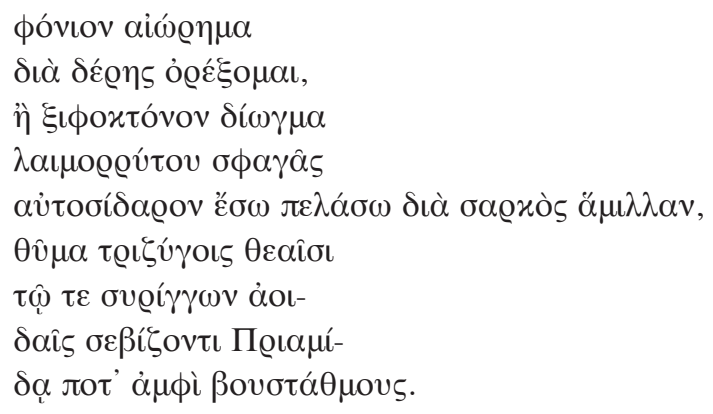

un lazo asesino por mi cuello extenderé o un golpe de espada mortal de degüello que derrama sangre, desnudo hierro a través de la carne hundiré en el cuello, como sacrificio al trío de diosas y al Priamida que las venera con cantos de siringas en aquel momento junto a los establos.

En estos versos, sin embargo, no creemos que quepa ver contradicción con los anteriores, sino que profundizan en lo que quiere Helena conseguir y ha hecho explícito ya antes, como expondremos más adelante.

3.1. Los vv. 298-302 han sido atetizados por varios editores debido a diversas razones: por esa supuesta incongruencia en el modo de proponer el suicidio, pero también por cuestiones gramaticales y de estilo.

${ }^{28}$ Quijada 1991, sobre la resis de Helena, vv. 255-305, pp. 59-61. 
Entre otras ediciones relevantes que atetizan los versos, cabe señalar la de Dindorf, que elimina el pasaje 299-302 remitiendo a la autoridad de Hartung, ${ }^{29}$ atétesis aceptada por Wilamowitz-Moellendorff, ${ }^{30}$ por Murray ${ }^{31}$ y por Diggle, quien remite a Clark y Hartung. ${ }^{32}$ También las ediciones comentadas más recientes de Dale, Kannicht y Burian los atetizan aunque los argumentos no siempre son coincidentes.

A. M. Dale, en la introducción y en el comentario de su edición, ${ }^{33}$ considera estos versos una interpelación fundamentalmente por tres razones: porque el clímax se produce en los vv. 352 ss. por lo que esta anticipación es innecesaria; pues el rechazo a la muerte por lazo es incongruente con la noticia de la muerte de Leda; y porque, en su opinión, obstaculizan la fluidez de la resis. También R. Kannicht los considera una interpolación de actor, pero sobre todo por problemas gramaticales: ${ }^{34}$ piensa que del v. 298 debe pasarse al 303 por ser incompatible con los vv. 299-302 la forma del v. 298 que transmiten los manuscritos; considera asimismo que en los vv. 353-356 debe verse el clímax, ${ }^{35}$ por lo que juzga innecesarios los vv. 298 ss. Estas opiniones son compartidas por P. Burian, que se suma a los argumentos de los predecesores y, como Kannicht, llama la atención sobre el deseo que manifiesta Helena de ser una víctima en un sacrificio a los que participaron en el "Juicio de Paris". ${ }^{36}$

Por el contrario otros editores mantienen estos versos, como G. Hermann $^{37}$ y en particular H. Grégoire, que en su edición para Les Belles

${ }^{29}$ Señala Dindorf 1869: "299-302 versus spurios eiecit Hartungus”.

301963 , p. 243.

311909.

321994.

33 1967, introducción pp. XXXI-XXXIII y 86 ss.

34 1969, tomo I, pp. 82 s., y tomo II, pp. 98 s. respectivamente.

35 Cf. 1969 tomo II, p. 111: "In diesem Passus werden Sprache und Metrik durch ihre Exuberanz zum sinnenfälligen Ausdruck des Pathos der Selbstvernichtung”. Añade Kannicht que aquí no contempla Helena la posibilidad de suicidarse por envenenamiento, como lo hace la sofoclea en fr. 178 Radt, donde dice que debería suicidarse bebiendo sangre de toro, pero Bañuls \& Crespo 2007, aquí pp. 144 s., señalan que no cuadra en boca de una mujer sofoclea una manifestación de este tipo y sugieren atribuir las palabras a Antenor.

36 2007, pp. 207-210.

37 1837; la numeración de los versos es diferente: los vv. 298-302 son los vv. 306310 . 
Lettres $^{38}$ explícitamente rechaza la atétesis y hace una indicación en nota muy coherente con las constantes alusiones que podemos ver en esta tragedia a Odisea, comentadas en su introducción: señala que con ese rechazo a la muerte por ahorcamiento evoca la escena del castigo a las sirvientas en Odisea, XXII, concretamente en el v. 462, donde Telémaco dice que no quiere darle a las sirvientas desleales una muerte digna.

Este verso de Odisea forma parte de un pasaje muy interesante. Odiseo, inmediatamente después de matar a los pretendientes, incluso antes de limpiarse él mismo y ponerse ropas adecuadas, quiere limpiar su casa, esto es, la sala del palacio llena de cadáveres y sangre, y eliminar a los criados desleales. Por ello ordena a Euriclea que separe a las criadas traidoras, doce según la anciana nodriza, y a Telémaco que les obligue a limpiar la sala, para que sus últimos recuerdos sean los cadáveres de sus amantes, y luego las mate con la espada, vv. 443-445. Odiseo quiere limpiar por completo su casa, incluso del recuerdo positivo que pudieran tener algunas criadas de aquellos varones y, al ordenar que las maten, se refiere a la muerte por espada, sin duda porque es el tipo de muerte en que piensa un soldado. Pero Telémaco reflexiona sobre esa orden de su padre, que no considera correcta, porque no se trata de un varón enemigo, sino de esclavas que han traicionado a su madre y a él en tanto que representantes del padre en su casa y que, por ello, merecen la muerte más infamante, vv. 462 ss.:

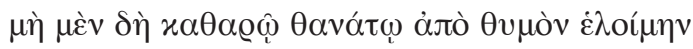

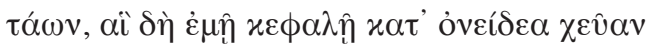

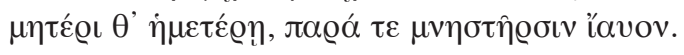

No quiero quitarles la vida con una muerte pura a esas que vertieron oprobio sobre mi cabeza y sobre nuestra madre y que yacían con los pretendientes.

Telémaco, en lugar de discutir la orden con Odiseo, la cambia, con lo que, además de modificar sobre la marcha una decisión improcedente, demuestra que ya es adulto, que ya puede tomar decisiones por su cuenta. ${ }^{39}$ Se trata, sin duda, de unos versos muy relevantes en el desarrollo del final

381950.

${ }^{39}$ Heubeck and Russo 2004; del canto XXII, texto crítico de Fernández-Galiano y comentario de J. Russo. Cf. las observaciones de Russo a los vv. 435-445. También se ocupa de esta condena Cantarella 1996, subapartado "En la casa de Odiseo: el ahorcamiento de las esclavas infieles", pp. 15 ss. 
de Odisea, en los que Telémaco explícitamente muestra su opinión sobre la forma de matar a las sirvientas y a continuación hace los preparativos

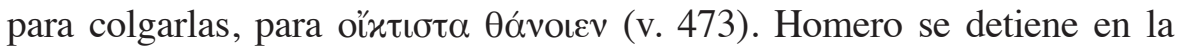
descripción de esos preparativos y de la muerte de las mujeres, que ha de ser un castigo ejemplar porque se trata de sirvientas infieles a sus señores.

Como Grégoire, más recientemente también consideran auténticos los versos E. P. Garrison y E. Calderón. La especial relevancia de la tragedia Helena es puesta de relieve por Garrison, que en Groaning Tears añade un capítulo a la reelaboración de su tesis doctoral, Some Contexts of Suicide in Greek Tragedy, el capítulo 6, "Conclusions: Suicide in Euripides'Helen": considera a esta tragedia una especie de microcosmos del suicidio, donde se presentan todas las variantes posibles. ${ }^{40}$ Garrison rechaza las atétesis de Dale y Kannicht, cuyos argumentos, a su juicio, se basan "more on the sentiment of the lines than on the grammar and language" (p. 173). Comparte la visión irónica de Helena y de la tragedia que manifiestan algunos estudiosos, lo que la lleva a extraer conclusiones sobre la actitud de la heroína que, a nuestro parecer, no encuentran refrendo en el texto, como es la opinión de que Helena rechaza el suicidio por lazo debido al deseo de preservar su belleza. Sólo una interpretación en la que se vea una intención irónica o claramente cómica por parte del autor justifica esta postura, que no podemos compartir, porque Helena reiteradamente rechaza su belleza.

En ese rechazo de la muerte por lazo, que es calificada con un adjetivo

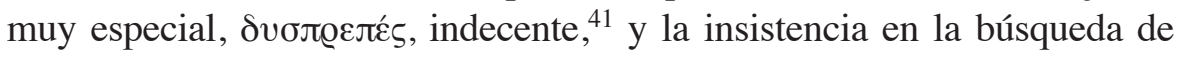

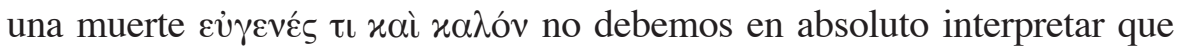
Helena se preocupa de su belleza, sino por la dignidad de la actitud y por la nobleza del acto en la misma línea en que se manifiesta, por ejemplo, Macaria en Heraclidas en el último verso de la resis en la que comunica

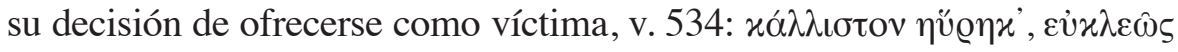
$\lambda$ ıлєîv ßíov, "lo más hermoso he descubierto, con honor abandonar la vida". En este verso se condensa toda la nobleza del personaje. Tampoco creemos que la reiteración de los posibles modos de suicidarse en los

${ }^{40}$ Las dos obras ya han sido citadas en las notas 6 y 7; para el capítulo 6, cf. pp. 168-179. Más allá de la exageración de indicar que se pueden ver en Helena todos los modos de suicidio, compartimos la opinión de la autora de que se trata de una tragedia en la que el suicidio está presente en muchas escenas.

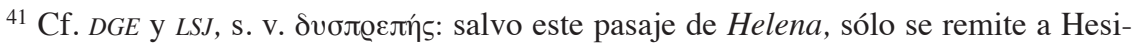

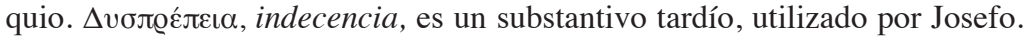


vv. 351 ss. esté motivada por el horror que siente ante el acto en sí del suicidio, ${ }^{42}$ sino que se trata más bien de una reiteración en gradatio.

Por su parte, Calderón, que también defiende la autenticidad de los versos, ${ }^{43}$ aduce como paralelo el fr. $854 \mathrm{~N}^{2}$ que Estobeo atribuye a Heracles y que se supone puesto en boca de Mégara, probablemente cuando reflexiona sobre lo ineludible de la muerte de Anfitrión, de ella misma y de sus hijos: 44

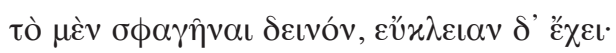

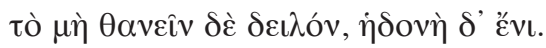

Ser degollado es terrible, pero comporta buena fama; no morir es cobarde, pero hay en ello placer.

Lico ha urgido a Anfitrión, a Mégara y a los niños, que se han refugiado en un templo, a que pongan fin a su vida, como les había ordenado. Anfitrión ha intentado retrasar el cumplimiento de esa orden con la esperanza de que Heracles vuelva a tiempo para evitarlo, pero Mégara cree que ya no hay salvación posible para ellos y reflexiona sobre la manera de morir. Tras mencionar el amor que siente por sus hijos, que, como antes dijo, están pegados a ella y preguntan por su padre, manifiesta que tampoco ella, como el anciano, desea morir, pero que es ineludible, vv. 281 ss.:

\section{[...] xaі̀ тò $x \alpha \tau \theta \alpha v \varepsilon i ̂ v$}

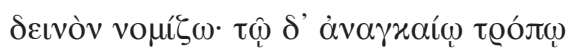

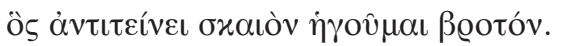

También yo considero terrible el morir; pero considero necio al mortal que se opone a un hecho ineludible.

Por ello, ante lo inevitable de la situación, reflexiona sobre los diferentes medios que puede utilizar para darse muerte: no quiere morir abrasada y con ello ser motivo de irrisión, lo que ella considera peor que

${ }^{42}$ Garrison 1995, p. 174: "The motivation, e.g., desire for good reputation, may be honorable, but the act itself is brutal and frightening. Helen clearly shrinks from the act as she demostrates here and in her lyric return to the question at $351 \mathrm{ff} . "$

432007 , notas a la traducción, pp. 60 s.

${ }^{44}$ Probablemente un buen lugar para este doblete sería cuando Mégara rechaza la posibilidad de morir quemados en el interior del templo, vv. 282 ss. Nauck, a pesar de la indicación de Estobeo, atribuye el fragmento a Heraclidas. 
la muerte (vv. 284 ss.). Mégara argumenta que la dignidad del linaje de Anfitrión, conquistada con la lanza, no puede malograrse, vv. 288 s. Forzado a aceptar Anfitrión que Heracles no conseguirá salir a tiempo del Hades para salvar a su familia, desiste de las dilaciones y, dando muestra de la valentía que cabe esperar de él, ofrece su cuello a Lico para que hunda en él la espada, ${ }^{45}$ vv. 319 s.:

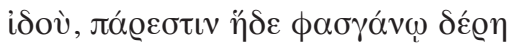

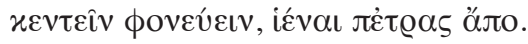

Mira, aquí está mi cuello presto para que con el cuchillo lo golpees, para el asesinato, para que me arrojes desde una roca. ${ }^{46}$

Una muerte que recuerda un sacrificio, como hace explícito Mégara cuando sale de palacio con sus hijos, ataviados todos para morir. Las primeras palabras que dirige a Lico al salir de palacio hablan del sacrificio, vv. 451 ss.:

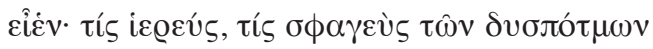

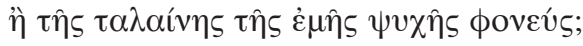

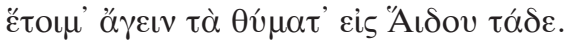

Bien, ¿quién es el sacerdote, quién el degollador de estos desdichados o el asesino de mi desgraciada alma? Preparada para conducir estas víctimas sacrificiales al Hades.

Mégara da por sentado que Lico les dará muerte mediante la espada

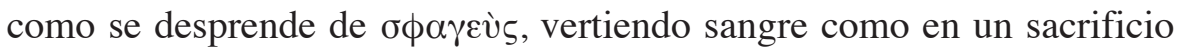
cruento. Lo que nos interesa destacar aquí es que la familia de Heracles, acosada por Lico, no quiere morir de una manera indigna o que pudiera provocar la irrisión de los enemigos, sino que Mégara y Anfitrión optan por un modo de morir que sea apropiado al linaje al que pertenecen, y por ello no se ha suicidado Mégara en el interior del palacio, sino que sale

45 Ofrece su cuello, como una víctima sacrificial; sobre los sacrificios cruentos

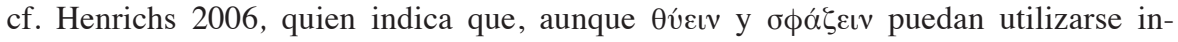

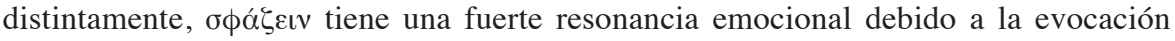
del derramamiento de sangre; para el vocabulario de los sacrificios en Eurípides cf. Calderón 2011.

${ }^{46}$ Como en el caso de Ión, no creemos que se deba suponer aquí que el anciano plantea dos posibles formas de morir, a espada y por despeñamiento, sino que esa segunda referencia debemos interpretarla como lo que supone que hará con su cadáver. 
ofreciéndose para el degüello, lo que le permite además considerarse a sí misma y a los niños víctimas sacrificiales cuya sangre se va a verter. ${ }^{47}$ Aunque no se trate de suicidios, sino de muertes impuestas, estos versos nos parecen muy interesantes para la interpretación de los vv. 298 ss. de Helena, porque vemos en ellos una explícita reflexión sobre la mejor forma de morir, la más adecuada a la noble posición de las personas que se enfrentan al terrible paso. Aquí, en boca de Mégara, vemos una gradatio en este caso en la aceptación de la muerte, que lleva desde la asunción del hecho ineludible a la presentación como víctimas sacrificiales, pasando por la reflexión sobre el modo de morir más digno.

3.2. Los paralelos de los vv. 298-302 de Helena que aducen tanto Grégoire como Calderón nos parecen muy pertinentes, y en la misma línea de aceptación de los versos afirma F. Silva que Helena quiere morir como un héroe, como Ayante, de cuyo suicidio se ha enterado por Teucro. ${ }^{48}$ Ayante muere con la espada de Héctor, el regalo que le hiciera su enemigo; se suicida haciendo responsables a los Atridas de su infamia y de su muerte y, por ello, reclama venganza a las Erinias al verter su sangre. En claro contraste con esta muerte, Leda, que no puede soportar la vergüenza por la supuesta infamia de su hija, se suicida por lazo, como también Yocasta en Edipo Rey, que no puede soportar el horror de las aberrantes uniones y de la nueva descendencia que ha engendrado. Esa comparación entre la muerte de Ayante y las de Leda y Yocasta en un mismo autor permite deducir que el ahorcamiento es una muerte propia de mujeres que reconocen el deshonor del que se han hecho acreedoras.

Es significativo que la Yocasta de Sófocles se suicide en el interior de casa, en el tálamo, el lugar donde cometió los actos aberrantes, mientras que la Yocasta de Eurípides en Fenicias no utiliza ese medio: como ya dijimos, se suicida sobre los cadáveres de sus hijos con la espada que los ha matado en el mismo campo de batalla y cayendo sobre ellos. En Fenicias Yocasta no es una mujer avergonzada y horrorizada por actos cometidos por ella junto con el hijo-esposo, sino la madre que, presa de

${ }^{47}$ Podría pensarse que Mégara quiere convertirse en un sacrificio cruento dedicado a Hades porque en el Hades está Heracles; sin embargo, las palabras tanto de Mégara como de Anfitrión no dan apoyo a esta idea.

${ }^{48}$ Cf. Sousa e Silva 2005, p. 211. La motivación de ese deseo es, con todo, diferente: en el caso de Ayante es la imposibilidad de seguir viviendo una vida que se ha convertido en motivo de irrisión para sus enemigos y de vergüenza para los suyos. 
un dolor insoportable al ver desaparecida su descendencia masculina, es decir, el futuro de su oikos, ${ }^{49}$ se quita la vida utilizando el mismo medio que quitó la vida a sus hijos.

Fedra también usa la soga para que crean que ha sido violentada y no puede resistir la infamia, pero precisa de un escrito que elimine de su persona toda posible responsabilidad. Por ese motivo, para que no pueda haber sombra de sospecha sobre su honor, al comienzo de la obra la vemos optar por otro tipo de suicidio, el de la inanición. Del mismo modo Evadne decide fundirse con el cadáver de Capaneo en la pira funeraria y no se suicida mediante lazo: hubiera podido arrojar alguna sospecha sobre los motivos de esa muerte, que es una muerte desmedida para un amor desmedido.

Como ellas, también Helena quiere que quede clara su inocencia con respecto a las faltas que se le atribuyen, desea que se sepa que ella no ha cometido ninguna infamia ni ha permitido una unión con el rey Teoclímeno. Pero no opta por una muerte por inanición ni por ser abrasada en una pira, sino que quiere verter su sangre como en un sacrificio para que ésta recaiga sobre el que la empuja a la muerte, sobre el bárbaro que anhela forzar las bodas.

3.3. Esa preferencia por la espada y el consiguiente deseo de que recaiga sobre Teoclímeno la sangre, es acorde con lo que leemos en el segundo pasaje, vv. 351 ss.: mientras se dispone a entrar en palacio a consultar a Teónoe por indicación del coro, entona una nueva monodia, en cuya primera parte reitera sus deseos de morir si es cierto el rumor de que Menelao ha muerto. Como señalan Dale, Kannicht, Burian y otros estudiosos, aquí podemos ver el momento culminante de la expresión de su desesperación, lo que está muy bien marcado en la forma métrica, tróqueos y el hexámetro dactílico del v. 356 con el que se enfatiza el carácter heroico de esa muerte. ${ }^{50}$ Pero la aceptación de esta gradatio en la manifestación del pathos no debe llevar a la eliminación de los vv. 298 ss., sino a ver en ellos una anticipación en la que Helena en una resis impregnada de

${ }^{49}$ Por ello el papel de Edipo en esta obra es prácticamente nulo: es presentado como un viejo acabado, que no sale a escena hasta el duelo final por los fallecidos, aunque lo que se está decidiendo es algo tan fundamental como el futuro de su ciudad y el de su linaje.

${ }^{50}$ Para la métrica del amebeo de los vv. 330-384, además de los comentarios ya citados, cf. Quijada 1991, pp. 193 s. 
emotividad focaliza su atención en la causa inmediata de la decisión de suicidarse, el deseo de evitar unas nupcias infamantes. La relación entre esas dos reflexiones sobre el mejor modo de morir está reforzada porque a ambas sigue una referencia a los daños que la belleza ha causado a las mujeres, también en gradatio: en los vv. 303 ss. Helena deplora la desgracia que a ella le ha acarreado su belleza y termina el amebeo cantando las desdichas que esa belleza ha acarreado a muchas mujeres, vv. 362-374, y la comparación con otras dos bellas y desgraciadas mujeres míticas, Calipso y Cos, a las que perdió su belleza, vv. 375-383; afirma al final, en los vv. 383-385, que su desdicha es aún mayor porque ha causado desgracias a una gran cantidad de personas.

Es cierto que Helena en vv. 351 ss. no se decanta abiertamente por una de las dos formas de morir, pero se desprende de sus palabras que prefiere verter la sangre que explícitamente considera como un sacrificio a los que son los responsables últimos de su situación, las tres diosas que compitieron en el concurso de belleza y el pastor Paris que resolvió el concurso. Esa minuciosidad al referirse a la muerte por espada, haciendo evidente lo que los versos anteriores callaban, es decir, que esta muerte provoca derramamiento de sangre, demuestra que es la que Helena prefiere, la que la presenta como la víctima impoluta de un sacrificio.

El deseo de que su sangre se vierta y en consecuencia precise venganza es acorde con lo que en las escenas posteriores al reconocimiento de los esposos pretende hacer Menelao, si Teónoe no les presta ayuda. Varias veces él habla de un eventual suicidio doble, de matar a Helena y suicidarse antes de permitir que ella sea forzada a una boda con Teoclímeno y él muerto vilmente por el rey egipcio, por ejemplo, v. 842. Pero en una escena se desarrolla especialmente el motivo: en el agón con Teónoe en el que los esposos piden a la joven sacerdotisa que permita a Helena regresar a casa y poder ser de nuevo la amante esposa de Menelao y la diligente madre de Hermíone. Menelao amenaza con matar a Helena y clavarse él mismo la espada en el hígado, como los otros héroes, es decir, amenaza con verter la sangre de ambos sobre la tumba de Proteo de modo que fluya hasta él y se convierta en una mancha, oprobio eterno para quien debió preservar a Helena para su esposo e indirectamente para Teónoe, que no ha sabido respetar la voluntad del padre ni valorar la justicia, vv. 982 ss.

Menelao reitera el deseo de verter sangre si es necesario porque sabe la importancia que tiene en la moral heroica y, en general, en el pensa- 
miento griego. Y esto concuerda con lo que manifestara antes Helena en los versos que nos ocupan, donde la heroína se presenta como una víctima sacrificial: ella, que se ha mantenido pura durante tantos años, prefiere convertirse en víctima sacrificial para evitar ser mancillada y para que recaiga el oprobio sobre el responsable, el bárbaro que quiere obligarla a una unión infamante. Los vv. 298-302, por lo tanto, no sólo no deben ser atetizados, sino que preparan la culminación del pathos que vemos en los vv. 353-360 y aportan información imprescindible sobre la causa de su elección y sobre lo que busca conseguir.

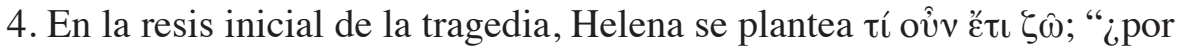
qué, pues, aún vivo?" (v. 56): consciente de la infamia que, aunque sea injustamente, recae sobre ella, manifiesta con estas palabras que a ojos de cualquiera sería esperable que buscara la muerte. A continuación explica la causa de que no lo haya hecho: Hermes le ha asegurado que volverá a casa con su esposo. Pero las terribles noticias que le ha traído Teucro provocan dudas sobre la veracidad de los antiguos anuncios de Hermes, a la luz de las sospechas que Teucro tiene de la muerte de Menelao, que, en todo caso, ha desaparecido en el mar; dudas que se van alimentando por la angustia que Helena siente a causa de la prolongada situación de indefensión en la que se encuentra.

Ante la posibilidad de que realmente Menelao haya muerto, retoma Helena la idea del suicidio que expresara en el prólogo y la desarrolla en dos pasajes en una gradatio emotiva: primero en una resis en la que acusa al responsable inmediato de su situación, a Teoclímeno, causante de su eventual suicidio, una muerte que quiere que sea acorde a ella y a su situación, muerte por espada que provoque derramamiento de una sangre que debe ser expiada; después, al final del amebeo que precede a su entrada en palacio, reitera los deseos de suicidarse, en este caso indicando explícitamente que se considera una víctima sacrificada a los responsables de su infamia, las tres diosas y Paris, sobre los que recaería su sangre.

En este contexto consideramos que los vv. 298-302 no son innecesarios ni incongruentes con respecto a los vv. 353-360, sino que, al contrario, constituyen un avance del clímax de la expresión del pathos en el que se adelanta la preferencia por una muerte cruenta que convierte a Helena en una víctima sacrificial cuya sangre se derrama y por ello debe ser expiada. Los causantes de la situación en la que ella se encuentra y sobre los que se quiere hacer recaer su muerte son las diosas que 
se sometieron al concurso de belleza y el joven Paris, que la utilizaron como moneda de cambio, como bien se indica en el segundo pasaje, pero también el bárbaro, el rey egipcio que la quiere forzar a unas nupcias odiosas y que la podrían obligar a poner fin a su vida.

\section{BIBLIOGRAFÍA}

\section{Ediciones}

Burian, P., Euripides. Helen, Oxford, Aris \& Phillips Classical Texts, 2007.

CAlderón, E., Eurípides. Tragedias IV. Los Heraclidas. Helena, Madrid, CSIC-Tirant Lo Blanch, 2007.

Dale, A. M., Euripides. Helen, Oxford, Clarendon Press, 1967.

Diggle, J., Euripidis Fabulae, III, Oxford, Oxford University Press, 1994 (Oxford Classical Texts).

Dindorf, W., Poetae Scenici Graeci, Leipzig, B. G. Teubner, 1869 (5 ed.).

GréGoIRe, H., Euripide V. Hélene-Les Phéniciennes, H. Grégoire \& L. Méridier, Paris, Les Belles Lettres, 1950.

Hermann, G., Euripidis Tragoediae. Helena, Leipzig, Weidmann, 1837.

Heubeck, A., \& J. Russo (eds.), Omero. Odissea VI, trad. de G. Privitera, Milan, Arnoldo Mondadori Editore, 2004 ( $7^{\mathrm{a}} \mathrm{ed}$.).

Kannicht, R., Euripides. Helena, 2 vols., Heidelberg, Carl Winter Universitätsverlag, 1969.

Murray, G., Euripidis Fabulae, III, Oxford, Oxford University Press, 1909 (Oxford Classical Texts).

Owen, A. S., Euripides. Ion, Oxford, Clarendon Press, 1971 (1 ${ }^{\text {a }}$ ed. 1939).

Pellegrino, M., Euripide. Ione, Bari, Palomar, 2004.

\section{Bibliografía secundaria}

Bañuls, J. Vte., \& P. Crespo, "Helénes apaítesis de Sófocles", O mito de Helena de Troia à actualidades, J. V te. Bañuls et alii (eds.), Coimbra, Universidade de Coimbra, 2007, pp. 105-163.

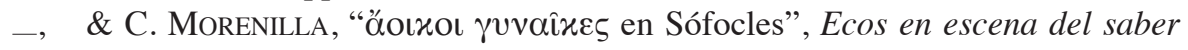
de las mujeres, F. De Martino \& C. Morenilla (eds.), Bari, en prensa.

Beltrán, J., "Terminología para la muerte y el suicidio (Lucrecio, Séneca, San Agustín, Sidonio)", CFC (StudLat), 4, 1993, pp. 27-37.

CALdERón, E., "El sacrificio y su vocabulario en Eurípides", Eusébeia. Estudios de religión griega, E. Calderón \& A. Morales (eds.), Madrid, Signifer Libros, 2011, pp. 37-73.

Cantarella, E., Los suplicios capitales en Grecia y Roma, Madrid, Akal, 1996 (trad. del original italiano, 1991).

Gantz, T., Early Greek Myth, London, John Hopkins University Press, 1993. 
GARCía PÉrez, D., "La muerte: su significación y su representación en la poesía griega", Nova Tellvs, 27/2, 2009, pp. 91-106.

GARrison, E. P., “Attitudes towards Suicide in Ancient Greece”, TAPhA, 121, 1991, pp. 1-34.

_, Some Contexts of Suicide in Greek Tragedy, University Microfilms International, 1987.

_, Groaning Tears. Ethical and Dramatic Aspects of Suicide in Greek Tragedy, Leiden-New York-Köln, E. J. Brill, 1995.

GERNET, L., Recherches sur le développement de la pensée juridique et morale en Grèce, Paris, Albin Martin, 2001 ( $1^{\mathrm{a}}$ ed. Paris, 1917).

Henrichs, A., "Blutvergießen am Altar: Zur Ritualisierung der Gewalt im griechischen Opferkult", Gewalt und Ästhetik. Zur Gewalt und ihrer Darstellung in der griechischen Klassik, B. Seidensticker \& M. Vöhler (eds.), BerlinNew York, W. de Gruyter, 2006, pp. 59-87.

Hooff, A. A. L. van, "Hatten Antike Selbstmörder eine Psyche?", Psychotherapie, 4 Jahrg., Heft 2, 1999, pp. 213-224.

_, From Autothanasia to Suicide. Self-Killing in Classical Antiquity, London, Routledge, 1990.

LORAUX, N., Maneras trágicas de matar a una mujer, Madrid, Visor, 1989 (trad. del original francés, 1986).

_, Las experiencias de Tiresias, Barcelona, El Acantilado, 2004 (trad. del original francés, 1990).

Morenilla, C., \& J. Vte. Bañuls, "Los excesos de Hermíone: el antimodelo femenino en Eurípides", El logos femenino en el teatro, F. De Martino \& C. Morenilla (eds.), Bari, Levante Editori, 2012, pp. 237-272.

NAVArro Antolín, F., "El suicidio como motivo literario en los elegíacos latinos", Emerita, LXV/1, 1997, pp. 41-55.

Pauly, A. F.-G. Wissowa et alii, Realencyclopädie der Classischen Altertumswissenschaft (R.E.), Stuttgart, Metzler, 1837 ss.: Thalheim, s. v. "Selbstmord", coll. 1134 s. y Eitrem, s. v. "Leda", coll. 1116-1125.

QuiJadA, M., La composición de la tragedia tardía de Eurípides. Ifigenia entre los tauros, Helena y Orestes, Vitoria, Universidad del País Vasco, 1991.

RoHDE, E., Psyche: Seelencult und Unsterblichkeitsglaube der Griechen, FreiburgLeipzig-Tübingen, J. C. B. Mohr, $1898^{3}$.

Seidensticker, B., "Die Wahl des Todes bei Sophokles", Sophocle. Entretiens sur l'antiquité classique 29, Fondation Hardt, Genève, 1983, pp. 105-153 (recogido en Über das Vergnügen a tragischen Gegenständen: Studien zum antiken Drama, J. Holzhausen (ed.), München-Leipzig, K. G. Saur, 2005, pp. 29-65). SousA E SiLVA, F., "Vida e morte na Helena de Eurípides", Ensaios sobre Eurípides, Lisboa, Cotovia, 2005, pp. 269-284.

SynOdinou, K., "Electra in the Orestes of Euripides. A Case of Contradictions", Métis, 3/1-2, 1988, pp. 305-320.

Wilamowitz-MoellendorfF, U. von, Analecta euripidea, Hildesheim, G. Olms Verlag, 1963 (reimpresión de Berlín, 1875). 